Abstract ID: 11

\title{
Reliability and construct validity of knowledge, attitude and practice of medical doctors on smoking cessation guidelines
}

Mohd Aznan Md Aris | Mohamad Haniki Nik Mohamed | Razman Mohd Rus | Nurjasmine Aida Jamani | Mohd Shaiful Ehsan Shalihin

Kulliyyah of Medicine, International Islamic University Malaysia

Introduction: Prevalence of active smokers in Malaysia is increasing despite availability of stop smoking clinics. Thus, practice of the healthcare professionals in providing smoking cessation intervention needs to be assessed. This study aimed to develop and validate a questionnaire to assess the knowledge, attitude and practice of medical doctors on national smoking cessation guidelines and factors contributing to the score. Methods: The 26 items consists of mixture of true/false questions; strongly-agree/agree/don't$\mathrm{know} /$ disagree/strongly-disagree response; and always/frequent/seldom/never response were created based on domain of 5A's (ask, assess, advice, assist, arrange) and 5R's (relevant, risks, rewards, roadblocks, repetitions). The questionnaires were distributed to 141 medical doctors. Reliability was determined using Cronbach's alpha for internal consistency while construct validity was assessed using factor analysis. Results: A high degree of internal consistency was observed for this 26 items (Cronbach's alpha=0.824). Subsequently, 2 items with poor inter-item correlations were removed. Factor analysis extracted 7 meaningful components from this remaining 24 items, in which 3 components with least items were deleted due to overlapping subscale with other components, leaving 4 meaningful components of $\left(1^{\text {st }}\right)$ practice ask, advice, assess and practice 5R's, $\left(2^{\text {nd }}\right)$ practice of assist and arrange for those willing to quit, $\left(3^{\text {rd }}\right)$ knowledge and $\left(4^{\text {th }}\right)$ attitude. These final 17 items still demonstrate high internal consistency with Cronbach's alpha of 0.832. Conclusions: This study indicates that this questionnaire is a reliable and valid tool to assess the knowledge, attitude and practice on stop smoking guidelines. Improvement can be made for attitude items in the future.

KEYWORDS: smoking, reliability and validity 